\title{
NOTES ON THE BOAS OF PUERTO RICO AND IMONA
}

\author{
Chapman Grant, Major, U. S. Army.
}

The two species herein treated seem very different in general aspect but show considerable similarity in squamation. The markings are really the surest and easiest means of identification, since most scale-counts overlap.

Dorsal spots neck to vent 70-80-Epicrates inornatus.

Dorsal spots neek to vent. 51-60-Epiorates monensis.

The postoculars of $E$. inornatus are 4 or rarely 3 . Of $E$. monensis 7 or rarely 6 .

\section{Epicrates inornatus (Reinhardt)}

Very few specimens of this species have been preserved in collections, there being only about half a dozen in the United States. Stejneger describes the type and variations in a scholarly manner in "The Herpetology of Porto Rico". To his description is added the fact that the lining of the mouth and the tongue are black and the eyes of the young are bronze color.

The first specimen of my collection eame from high up on Luquillo mountain. It is dark and of so uniform a color that the dorsal spots cannot be counted. Length $6^{\prime}$. The next two specimens were from the headwaters of the Mameyes River. Taken May 17, 1931. They mated the same day while being transported in a box. They would not eat, although a roomy eage with shelter was provided. Every imaginable food was offered them-small, live rabbits, small live chickens, live Anolis, cockroaches, milk, meat, fruit, eggs, etc. Finally they assimilated beef when force-fed. Upon being killed, July .20, 1931, the female was found to contain 32 embryos in eapsules $54 \times 30 \mathrm{~mm}$. The embryo being $90 \mathrm{~mm}$. long, the body $4 \mathrm{~mm}$. wide, the head like a bird's, almost spherical and about $6 \mathrm{~mm}$. in diameter, the eye $3 \mathrm{~mm}$. in diameter, pigmented. The markings on these two adults are very clear, there being about 73 dorsal spots, decidedly and clearly outlined with very dark brown, the center light walnut color but darker than the brown body color. Length $5^{\prime} 9^{\prime \prime}$ and $6^{\prime}$ respectively. Another specimen from near the City of Rin Piedras $2^{\prime} 101 / 2^{\prime \prime}$ long is a light tan color. In distinction to all other specimens seen the dorsal spots, 78 in number, are lighter instead of darker than the body color, with a suggestion of a darker border. 
Hence, light instead of dark spots are counted on this specimen. A postocular dark line is prominent in this specimen. The fifth specimen, $370 \mathrm{~mm}$. long, is one of a litter of 18, of which more may have escaped un-noticed, born in captivity at Río Piedras, in the possession of Mrs. T. J. Haydon. She had no suceess in feeding the young which all escaped or starved. It is impossible to count accurately the dark spots on this specimen because they are so broken up, but there appear to be about 70 . One of her adults constricted a guinea pig but would not swallow it.

This boa appears to be entirely inoffensive and strikes only when hurt. On the defensive, it frequently ties itself into a ball with the head entirely hidden within the folds of the body. It hisses loudly and ean strike with open mouth about one half the length of the body from a gathered position. It does not "coil".

I have measured several skins and several poorly mounted and alcoholic specimens and find none over $6^{\prime} 6^{\prime \prime}$ long, although stories persist of larger specimens.

This snake is partly arboreal, being frequently found in trees. W:hen disturbed, it descends and enters a hole at the base of the tree or makes for rocky places. It is apparently a nocturnal feeder but basks in the early sun before retiring to its lair. The lairs may be distinguished by the strong odor.

Amaral (1) has synonymized this species with E. subflavus Stejneger. Stull (2) makes the following remarks: "Doctor Amaral has obviously treated the South American members of this group, with which he is thoroughly familiar and of which he has examined large series of specimens, in a manner quite different from his handiing of the West Indian forms, which are almost entirely unrenresented in South American Museums. These species with which he is familiar, as well as those known only from the literature, are subjected to the most casual, and in most cases, ill-advised synonymizing. . . . ."

It seems reasonable to maintain this isolated form as a distinct species until large series are available for comparison. I am personally convinced that the species is distinct.

Fray Inigo Abbad y Lasierra, 1788 tells a "snake story" on this species which for its audacity of conception deserves repeating. $\mathrm{He}$ says, in substance that this snake inhabits houses and hunts rats at

Note: Mrs. Hajdon has found that the boas readily eat white rats although they constrict and kill more than they eat. It is interesting to consider what their natural food may have been before the relatively recent introduction of the rat. 
night. The snake fastens its head to the floor and raising its body in the air uses it as a flail to slay the rats.

\section{Epicrates monensis Zenneck.}

This species is admirably described by Stejneger in "The Herpetology of Porto Rico" from 5 specimens in the Hamburg Museum.

There is one specimen in the Field Museum.

My three specimens, all young, 390, 800 and $810 \mathrm{~mm}$. in total length respectively, agree with Stejneger's description, except in the following: scale rows at mid-body $40,44,46$, whereas he gives 43 as the maximum; subcaudals $74,75,87$, whereas his minimum is 79 and maximum 82 ; supralabials 12-13, 13-14, 14-14, whereas he gives 11-13, 13-13, 13-13, 13-13, 13-13. These amplitudes tend to show slightly greater differences from $E$. fordii than appear in existing descriptions.

The species is rare in collections and practically unknown to the inhabitants of Mona Island. The last recorded specimen, before mine, was taken in 1892.

There have been attempts made to synonymize this species with $E$. fordii, all of which have been rebutted. The last is Amaral (1) who is rebutted by Stull (2) as follows: "The form Epicrates monensis Zenneck is synonymized with $E$. fordii (Gunther), although it can be distinguished from the latter not only by its coloration, particularly the considerably smaller number of dorsal spots, but also by apparently constant differences in the numbers of seale rows, ventrals, and caudals. ...."

(1) Amaral, A. do, Valor Systematico de Varias Formas de Ophidios Neotropicos. Mem. Inst. Butantan, IV, pp. 1-68, 1929. ..... ., Lista Remissiva dos Ophidios do Brasil. Ibid., IV, pp. 70-125. . . . . . . Lista Remissiva dos Ophidios da Regiao Neotropica. Ibid., IV, pp. 126-271.

(2) Stull, Olive Griffith, Corrections to Some Recent Papers on Neotropical Snakes. Bul. Antivenin Inst. of Am. V, No. 2, pp. 39-41, Sept. 1931.

\section{Explanation of Plate XXXVIII}

Fig. 1. Epicrates monensis, young.

Fig. 2. Epicrates inornatus, young. 


\section{PLATE XXXVIII}

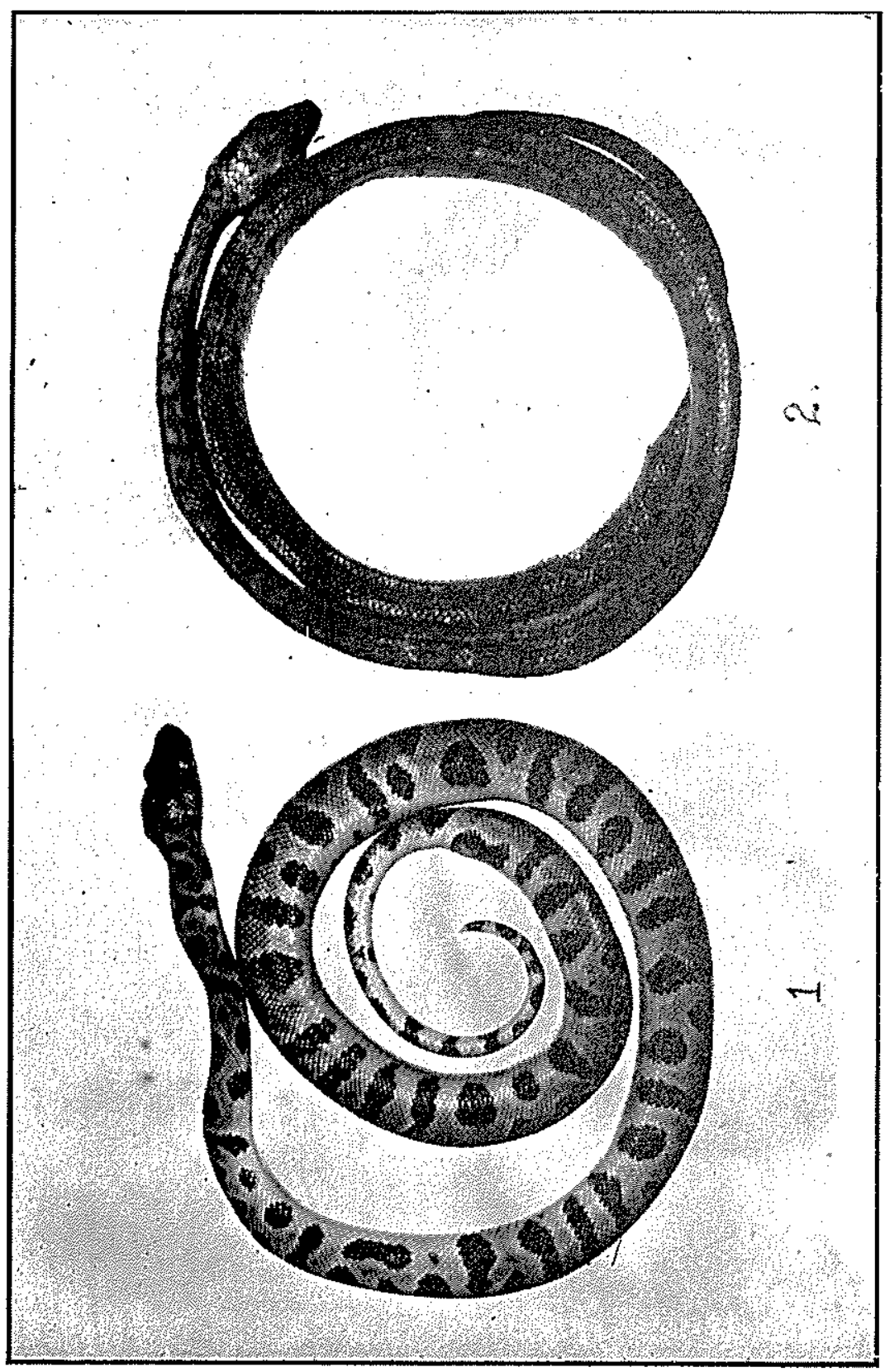


PLATE XXXIX

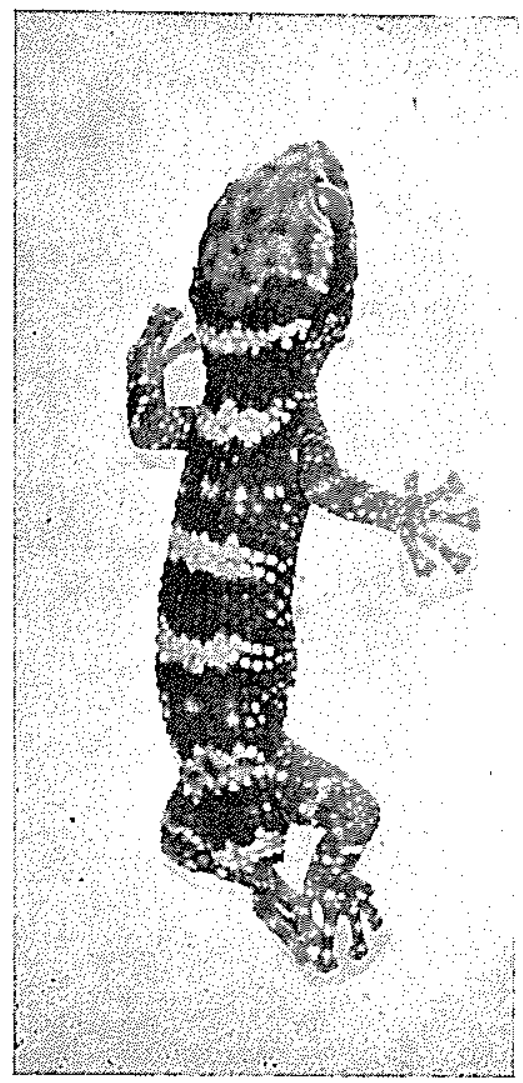


PLATE XL

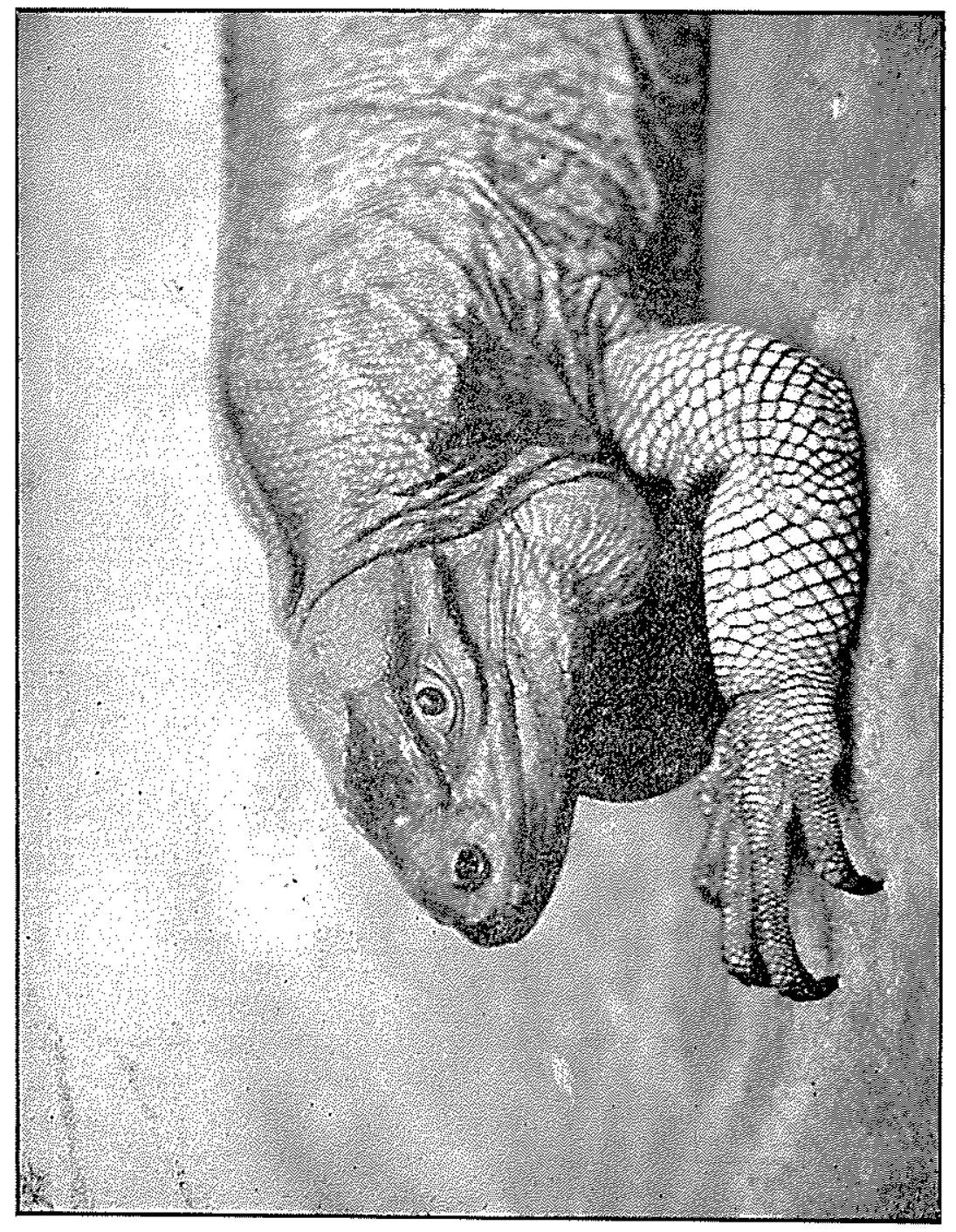



PLATE XLII

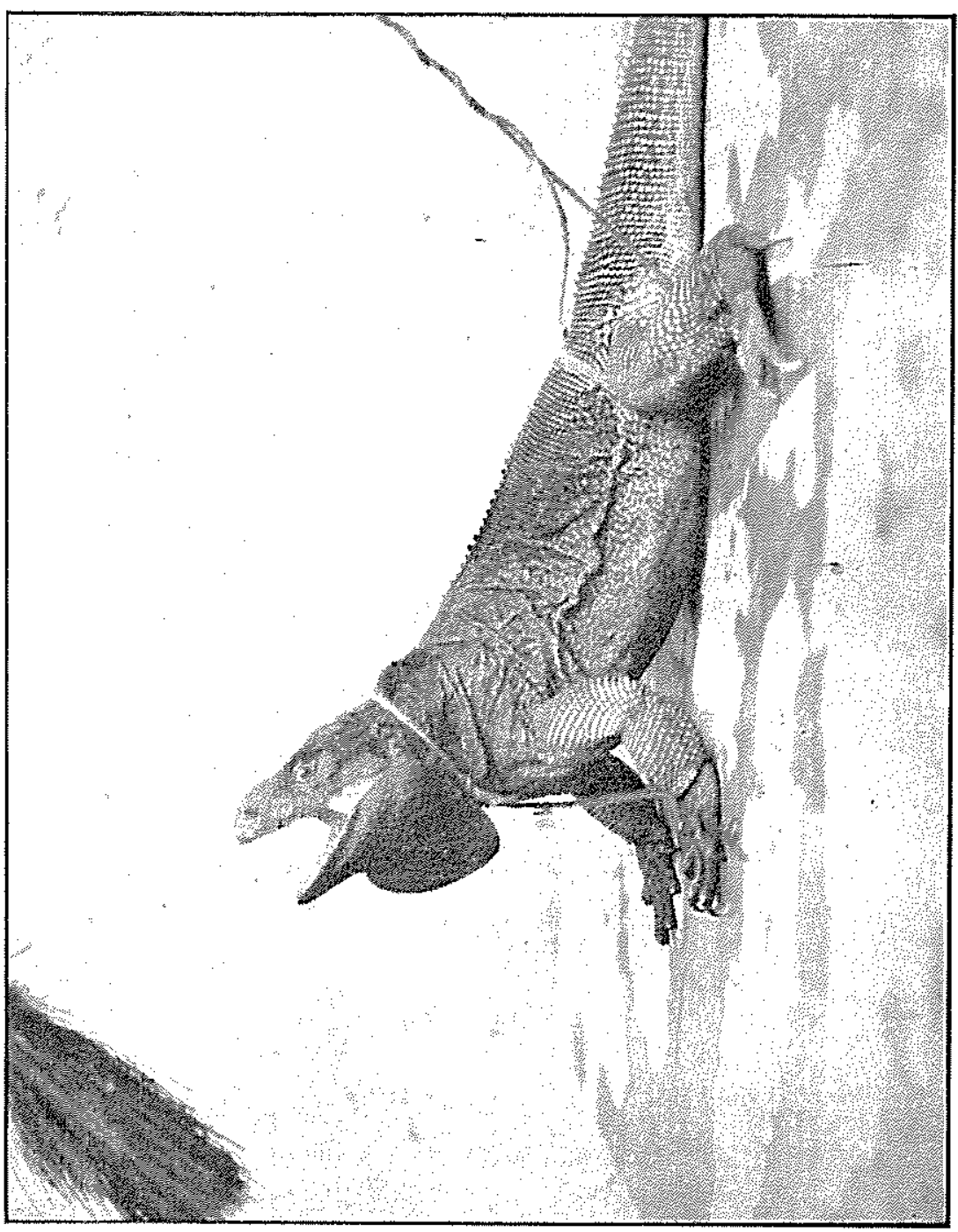

